\section{LA EMPERATRIZ ISABEL DE PORTUGAL CON EL PRÍNCIPE FELIPE EN BRAZOS (1529): EN BUSCA DE UN RETRATO PERDIDO DE ANTONIO DE HOLANDA}

EMPRESS ISABELLA OF PORTUGAL WITH PRINCE PHILIP IN ARMS (1529): IN SEARCH OF A LOST PORTRAIT BY ANTONIO DE HOLANDA

L'IMPÉRATRICE ISABELLE DE PORTUGAL PORTANT LE PRINCE PHILIPPE DANS SES BRAS: À LA RECHERCHE D'UN PORTRAIT PERDU D'ANTONIO DE HOLANDA

RESUMEN: En 1529 el pintor António de Holanda realizó varios trabajos pictóricos para el emperador Carlos $\mathrm{V}$ e Isabel de Portugal, entre ellos un retrato de la emperatriz con su heredero, el príncipe Felipe, en brazos, a la manera de la Virgen con el Niño. Este trabajo presenta una pintura que podría ser la versión más cercana a dicho retrato original, que se considera perdido.

PALABRAS CLAVE: emperatriz Isabel de Portugal; Felipe II de España; emperador Carlos V; António de Holanda; Luis de Morales; iconos religiosos; retrato a lo divino; Fundación Casa Medina Sidonia.
ABSTRACT: In 1529 the painter António de Holanda made several paintings in Toledo for the Emperor Charles $\mathrm{V}$ and his wife Isabella of Portugal, including a portrait of the Empress with her heir, Prince Philip, in arms, in the guise of the Virgin and Child. This paper presents a painting that could be the closest version of the original portrait, that is considered lost.

KEYWORDS: Empress Isabella of Portugal; Philip II of Spain; Emperor Charles V; religious icons; portrait in the guise of a religious painting; António de Holanda; Luis de Morales; House of Medina Sidonia Foundation.

\section{ROMERO DORADO, Antonio}

Centro de Investigación de la Historia de la Arquitectura Andaluza (CIHAA)

\section{Departamento de Historia del Arte Doña María de Padilla, $s / n$ 41004 Sevilla \\ antonio.romero.dorado.edu@juntadeandalucia.es ORCID ID: 0000-0002-4979-0491}

Este estudio se ha llevado a cabo en el marco del grupo de investigación HUM171 de la Universidad de Sevilla. de Holanda réalisa divers travaux pour Charles-Quint et pour Isabelle de Portugal, parmi lesquels un portrait de l'impératrice avec le prince héritier dans ses bras, le futur Philippe II, à la manière d'une Vierge à I'Enfant. Ce travail présente une peinture qui pourrait être identifié comme la version la plus proche de ce portrait original, considéré perdu.

MOTS-CLÉS: Impératrice Isabelle de Portugal; Philippe II d'Espagne; empereur Charles-Quint, António de Holanda; Luis de Morales; icônes religieuses; portraits divinisés; Fondation Maison de Medina Sidonia.

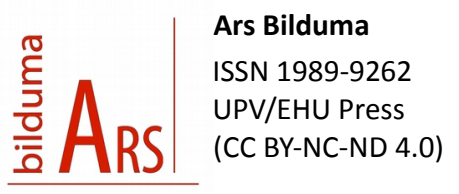

https://doi.org/10.1387/ars-bilduma.16586 BIBLID [(2018), 8; 41-61]

Recep.: 29/06/2016 Acept.: 25/10/2016 
Muito tempo ha que sou de Vossa Majestade e que tenho grandes deseios de o servir, e isto he ja herdado de meu pai António de Holanda, que a Imperatriz e o Imperador que estão na gloria mandaron o chamar a Toledo, para que os retratasse como fez, e assimesmo retraou a Vossa Majestade no colo da Imperatriz. ${ }^{1}$

El objetivo de este trabajo ${ }^{2}$ es dar a conocer una pintura de la Virgen con el Niño propiedad de la Fundación Casa de Medina Sidonia, que tiene su sede en Sanlúcar de Barrameda, en España (fig. 1). ${ }^{3}$ Se trata de un cuadro de pequeño formato, de $50 \times 43 \mathrm{~cm} .{ }^{4}$ pintado al óleo sobre lienzo. Desde el punto de vista compositivo es un tondo inscrito en un rectángulo, que contiene la imagen de busto de una mujer joven, elegantemente vestida y tocada, que sostiene en brazos a un niño de corta edad. El rectángulo y el círculo forman un marco fingido, compuesto por una moldura circular

1 Traducción al español: Mucho tiempo hace que soy de Vuestra Majestad y que tengo grandes deseos de servirle, y esto lo he heredado de mi padre António de Holanda, que la Emperatriz y el Emperador que están en la gloria mandaron llamar a Toledo para que los retratase, como hizo, y asimismo retrató entonces a Vuestra Majestad en el cuello de la Emperatriz. DE HOLANDA, F.: Carta del pintor Francisco de Holanda al rey Felipe II de España, 22 de enero de 1572 (en portugués). Archivo General de Simancas, Sección Estado, legajo 390, documento 87.

2 Este texto está dedicado a la memoria de Rocío Garrido Neva, que sentía especial predilección por esta pintura. Asimismo, quisiera expresar mi profundo agradecimiento a Liliane M. DahImann, presidente de la Fundación Casa Medina Sidonia, Rocío Garrido Neva, Fernando Cruz Isidoro, director del CIHAA, Luis Miguel Bernal Asencio, Antonio Moreno Ollero, Caridad López Ibáñez, José María Hermoso Rivero, Eduardo LamasDelgado, María Luisa Millán Salgado, Ana Diéguez-Rodríguez, Ana García Sanz y Luis Parejo Fernández.

3 Esta pintura es Bien de Interés Cultural (B.I.C.), integrante del Patrimonio Histórico Español, pues está afectada por la declaración como Monumento Nacional del Palacio ducal de Sanlúcar de Barrameda, según Real Decreto 727/1978, de 2 de marzo (BOE no 90 de 15 de abril).

4 Con marco $59 \times 53 \mathrm{~cm}$

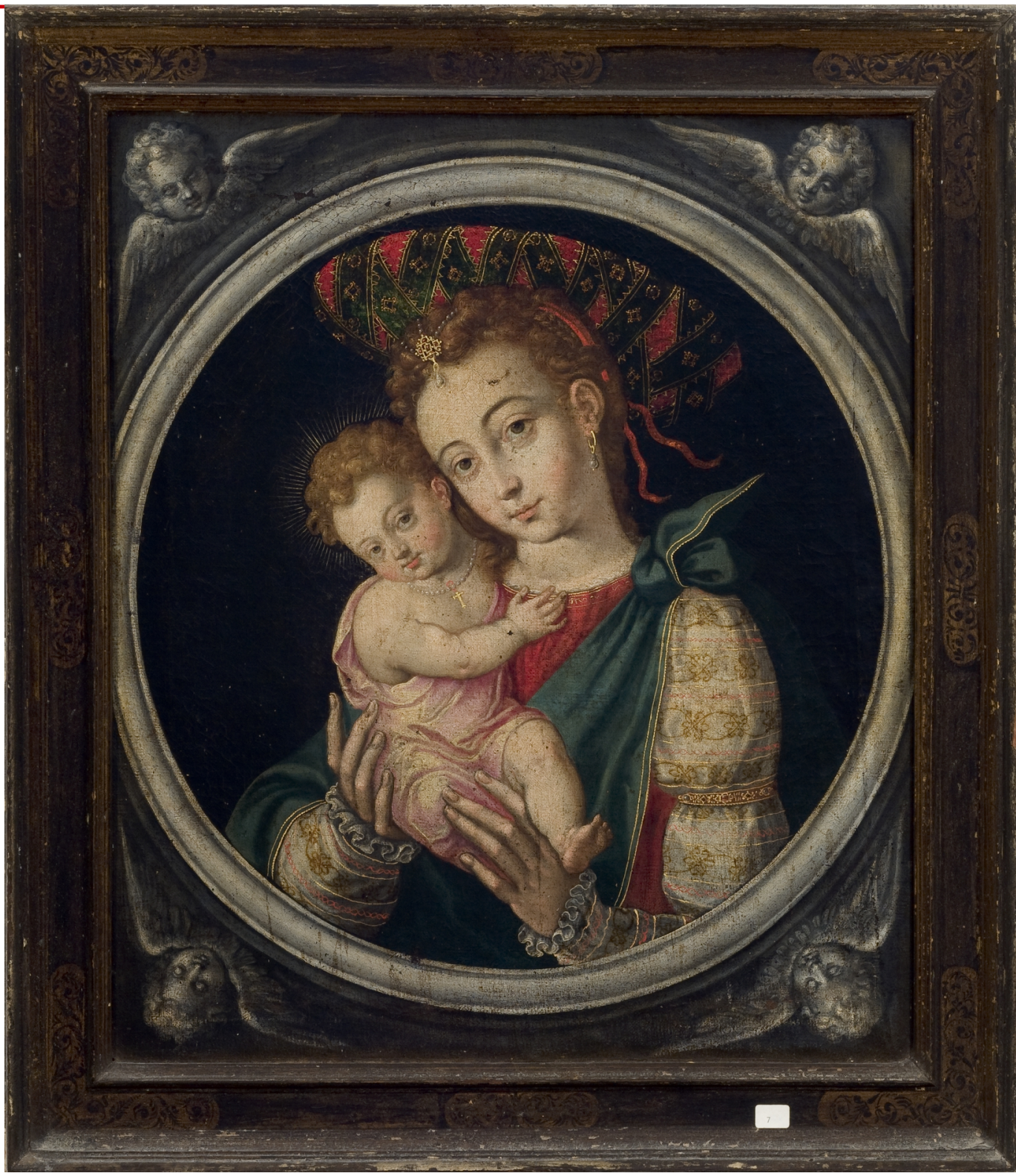

Fig. 1: Virgen con el Niño. @ Fundación Casa de Medina Sidonia 
convexa rodeada por cuatro querubines con las alas desplegadas, en actitud protectora de la escena. Todo este marco está realizado, según la técnica de la grisalla, en tonos grises claros y oscuros. Asimismo, la pintura tiene un marco verdadero de madera, realizado a cassetta y con la entrecalle decorada en las esquinas y en la parte central de los listones con roleos vegetales estofados.

Estamos ante una representación de la Virgen María con el Niño Jesús en brazos, por lo que iconográficamente hablando se trata de una Theotokos o madre de Dios. María sostiene a Jesús en sus manos, mostrándolo al espectador, mientras que el Niño se agarra a su madre pasándole un brazo por detrás del cuello. La actitud cariñosa entre madre e hijo hace de esta pintura un ejemplo de la iconografía mariana llamada eleúsa o Virgen de la Ternura, también denominada mater amabilis o glicofilusa, que significa "la dulce amante". Se trata de una iconografía de origen bizantino, de la que existen conocidos iconos, como la Virgen de Vladimir de la galería Tretiakov de Moscú, del siglo XII. En efecto, los rostros ladeados de ambos personajes, cuyos cabellos se rozan levemente, así como la mano del niño que casi se agarra al cuello del vestido de su madre, producen en la escena un efecto de gran intimidad. Asimismo, el tipo de sombrero que lleva la Virgen, del que hablaremos más adelante, sitúa la escena en un momento concreto del relato evangélico. Se trata de la Huida a Egipto, por lo que la obra puede considerarse una Virgen del Reposo o del descanso en dicha huida.

Estos sombreros fueron frecuentes en el arte de los Países Bajos del siglo XVI para representar a mujeres peregrinas o que están en escenas situadas a la intemperie. En el caso de Sanlúcar, estamos ante una versión muy refinada de esta prenda de origen popular, pues el ala está completamente forrada por una tela roja que parece de seda, sobre la cual se ha enrollado una cinta ancha de color verde oscuro, entretejida y orlada con hilos de oro siguiendo la técnica del brocado. El sombrero está atado a la cabeza mediante dos cintas estrechas de tela roja, cuyos extremos flotan a la altura del cuello en contraste con el fondo de la escena, profundamente negro, que parece aludir a un momento nocturno durante la huida a Egipto. La completa oscuridad del fondo, además, sirve al pintor para centrar la atención del espectador en las dos figuras representadas, permitiéndole una violenta iluminación que cae sobre ambos personajes y que resulta verdaderamente atrayente.

El efecto de esa luz, que procede de la izquierda, se aprecia con claridad en las cintas verdes del sombrero, que se muestran más iluminadas en ese lado, mediante veladuras. La suntuosidad del sombrero está en consonancia con el resto de los detalles de la indumentaria y con las joyas que lucen ambos personajes. El vestido de la Virgen tiene un cuerpo liso de color rojo, con escote a la caja ribeteado en oro y por el que asoma la lechuguilla de la camisa interior. Las mangas blancas de la camisa galana son de seda brocada en oro, ocre y rojo. Están abullonadas con una cinta de pasamanería colocada en mitad del brazo, decorada con una banda de cabujones engarzados fingidos. Asimismo, bajo las mangas afloran los puños de lechuguilla de la camisa interior. Completando el conjunto la Virgen lleva un manto de color azul-verdoso, anudado en el hombro derecho y ribeteado en oro con dos líneas paralelas lisas. Por su parte, el vestido del Niño, de color rosa palo tornasolado en amarillo, es una especie de capa o clámide. Esta prenda deja el hombro izquierdo al descubierto mientras que el derecho, que queda oculto, debe tener un nudo similar al del manto de la madre. La Virgen luce en el cabello un aderezo formado por tres sartas de perlas unidas en un joyel de perfil cuadrilobulado, del que cuelga una perla en forma de lágrima engastada en una pieza de oro, que queda sobre la frente. Por su parte, el pendiente que está a la vista es un sencillo arete de oro del que pende una perla también en forma de lágrima ensartada en una pieza de oro articulada. Asimismo, 
el Niño lleva un collar de perlas del que cuelga una sencilla cruz latina de oro, atada al collar con un hilo de color rojo y que actúa como presagio de la Pasión. El mismo sentido premonitorio suele darse a que el Niño muestre la planta de uno de sus pies, como en este caso, recordando al espectador que será perforado durante la crucifixión.

A partir de mediados del siglo XVI encontramos en la pintura española numerosas obras que representan a la Virgen con el Niño siguiendo de forma más o menos literal el mismo modelo que esta pintura de Sanlúcar. De hecho, esta obra de la Fundación Medina Sidonia está directamente conectada con otras muy populares. Se trata de las llamadas "vírgenes del sombrero" o "vírgenes gitanas" de Luis de Morales (ha. 1510-ha. 1586). Las numerosas versiones del tema realizadas por el divino Morales y por su entorno, demuestran el éxito que este modelo pictórico tuvo en España entre la clientela artística de la época. De hecho, las vírgenes del sombrero o gitanas se convirtieron en una suerte de icono, popularizado por Morales y reproducido por otros artistas del Siglo de Oro. ${ }^{5}$ La nómina de pinturas similares es francamente amplia, ${ }^{6}$ aunque los ejemplos más parecidos a la

5 Incluso hubo artistas italianos que reprodujeron esta iconografía, como Jacopo Zucchi, que hacia 1584 pintó un cobre de apenas un palmo de con "Nostra Donna con Christo in braccio in abito di zingana", encargada por el cardenal que Ferdinando de' Medici para regalar a Mateo Vázquez de Leca, secretario de Felipe II de España. VANNUGLI, A.: "La subida al Calvario de Scipione Pulzone para Marcantonio Colonna", Archivo Español de Arte, vol. 85, no 340, 2012, pp. 303-328, aquí véase p. 322.

6 Existen numerosas versiones de la Virgen del sombrero, como las del Museo de Bellas Artes de Boston (1), Fondo cultural Villar Mir (2), monasterio de las Descalzas Reales de Madrid (3), colección particular de Madrid atribuida a Pedro Mata (4), colección particular subastada en Sotherby's Londres en 2010 (5), colección particular de Madrid subastada en Christie's Londres en 2005 (6), colección Adanero de Madrid (7), colección Balanzó de Barcelona (8), colección Valderuey de Madrid (9), colección particular de Madrid procedente de la Gómez Moreno (10), convento de clarisas de Alba de Tormes (11), colección particular subastada en la Sala Retiro de Madrid en pintura de Sanlúcar son el conservado en el Museo de Bellas Artes de Boston, de Morales, ${ }^{7}$ el atribuido a Pedro Mata, en colección particular, ${ }^{8}$ y el conservado en las Descalzas Reales de Madrid (fig. 2), ${ }^{9}$ estos dos últimos muy parecidos entre sí.

Su denominación como "vírgenes del sombrero" no merece mayor detenimiento, pues se refiere al peculiar complemento que lleva la Virgen. El nombre de "vírgenes gitanas", en cambio, sí requiere de mayores explicaciones. Lo cierto es que todas estas imágenes tienen en común dos aspectos. Por un lado el manto anudado al hombro y por otro el característico sombrero de ala ancha con cintas enrolladas y entrecruzadas. Podemos suponer que el sombrero tiene su origen en los primitivos rodetes, formados por una rosca de paño que las mujeres se ponían en la cabeza para cargar y llevar sobre ella un peso. De esta manera podemos verlo en un dibujo de Hans Burgkmair de hacia $1510,{ }^{10}$ en el que unos gita-

2012 (12), colección Arango de Madrid (13), Museo de Arte Ashmolean de Oxford (14), Museo del Prado (15) y colección Abelló (16). La versión del Prado tiene un gran parecido con la tabla de Sanlúcar, pues presenta los mismos colores en el vestido, la camisa y el manto.

7 Véase la pintura en

http://web.archive.org/web/20160404141556/http://www.mfa.org/collections/object /virgin-and-child-34293 (consultado el 29/12/2016).

8 Actualmente en paradero desconocido, fue atribuido a Pedro Mata por MATEO GÓMEZ, I.: "Flandes, Portugal y Toledo en la obra de Luis de Morales. Las Vírgenes gitanas o del sombrero", Archivo Español de Arte, vol. 80, no 317, 2007, pp. 7-24, aquí véase p. 23.

9 Se trata de la obra identificada con el número de inventario 00610696. Fue Rocío Garrido Neva quien me informó de que en el Monasterio de las Descalzas Reales de Madrid, del Patrimonio Nacional de España, había un cuadro muy parecido al de Sanlúcar. Agradezco a Ana García Sanz, conservadora de dicho monasterio, haberme atendido amablemente en la solicitud de una fotografía de dicha pintura.

10 Conservado en el Museo Nacional de Estocolmo. 


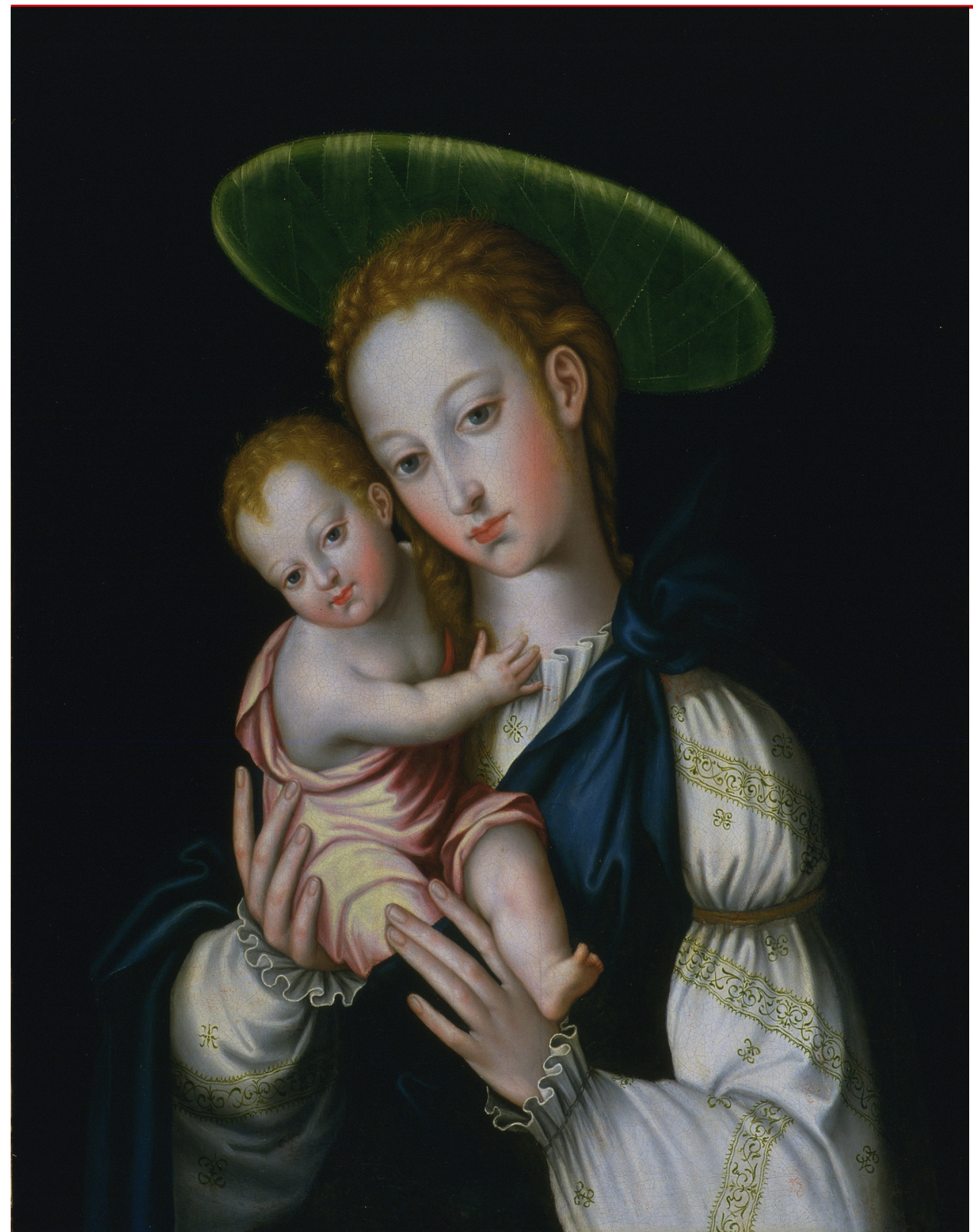

nos aparecen robando quesos mientras una gitana distrae a la propietaria diciéndole la buenaventura. Una variante evolucionada de estos rodetes son una especie de turbante, en cuyo interior se ha colocado una estructura de madera ligera, o de otro material, que le da mayor rigidez y superficie al tocado y que proporciona más sombra a quien lo lleva. De este modo, podemos verlo en fecha temprana, hacia 1515, en el Carro de Heno de El Bosco, en el Museo del Prado. Pero el mundo del sombrero y del tocado, en el ámbito neerlandés, fue muy rico y variado, tanto en su vertiente masculina como en la femenina, por lo que conocemos tocados masculinos similares, como el que lleva un hombre barbado en la citada obra de El Bosco o en su Ecce Homo del Museo Städel de Fráncfort, de cronología anterior. Asimismo, son muy significativas algunas pinturas de Lucas van Leyden, en que aparece de forma muy clara el mismo tipo de mujer que en la pintura de Sanlúcar. Se trata de las obras que representan a Moisés haciendo brotar agua de una roca (fechada en 1527), la Adoración del becerro de oro y la Curación del ciego de Jericó, ambas de hacia $1530-1531 .{ }^{11}$ En ellas se muestran varias mujeres con este sombrero y con el manto anudado al hombro, lo que les permite llevar un niño con la ayuda de un solo brazo. Esta manera de portar a los pequeños, que ya veíamos en el Carro de heno, suele asociarse con representaciones de mujeres peregrinas o nómadas, como podemos ver en las gitanas que aparecen en el tapiz franco-flamenco de hacia 1510, que se conoce como I a Visita de los Gitanos o en las mencionadas pinturas de van Leyden. ${ }^{12}$ Asimismo, suelen aparecer de esta guisa algunas mujeres que acuden a eventos multitudinarios celebrados a la intemperie, como en la Predicación de San Juan Bautista, del Museo Nacional de Arte Antiguo de Lisboa, atribuido con ciertos problemas a Gregório Lopes y datado entre

11 Respectivamente en el Museo de Bellas Artes de Boston, en el Rijksmuseum de Amsterdam y en el Museo del Hermitage de San Petersburgo.

12 Conservado en el Museo de Arte Currier de Manchester. 
1530 y 1550, en el Milagro de los panes y los peces, de Cornelis Massys, ${ }^{13} \mathrm{o}$ en la Predicación del Bautista de Brueghel el Viejo (1566). ${ }^{14}$ Del mismo modo este tipo humano puede observarse en obras en que simplemente aparecen mujeres con sus críos al aire libre, como en la Vista del foro romano desde el Capitolio de Hieronymus Cock, de 1551.

Por otro lado, en gran parte de Europa estaba muy extendida la creencia de que los gitanos procedían de Egipto. De hecho, en la península ibérica, adonde este pueblo había llegado principalmente en el siglo $X V$, se les llamó "egiptanos", gentilicio del que procede la palabra gitano. A principios del XVI, ya era frecuente entre los pintores del ámbito neerlandés y germánico representar a la Virgen durante la Huida a Egipto con un sombrero de ala ancha, ya que era una prenda apropiada para resguardarse del sol durante los viajes. Esto puede apreciarse en ejemplos tempranos, como el grabado de Durero que ilustra dicho tema, perteneciente a su serie de la Vida de la Virgen (1511) o en la pintura de Wolf Huber (ha. 1485-1553) inspirada en él. ${ }^{15}$ Asimismo lo vemos en la estampa sobre composición de Albrecht Altdorfer del mismo asunto, de hacia 1515-1519. Sin embargo, el sombrero que aparece en estas obras todavía no responde exactamente al modelo de rodete del que hemos hablado. Del mismo modo, sabemos por documento que el tipo de mujer pregrina, ataviada con turbante redondo y manto anudado al hombro, con el que llevar a los niños, ya se consideraba una imagen tópica de las gitanas, al menos desde 1528-29. Por entonces, se encargó a Andrea da Milano ${ }^{16}$ el grupo escultórico de la Lamentación sobre el cuerpo muerto de Cristo para el Santuario de la Virgen de los Milagros de Saronno, en

13 En El Escorial, Patrimonio Nacional, no de inventario 10014744.

14 En el Museo de Bellas Artes de Budapest.

15 En la Gemäldegalerie de Berlín.

16 También conocido como Andrea da Corbetta o Andrea da Saronno.
Lombardía. De hecho, el escultor recibió la indicación expresa de que incluyera entre las figuras a una gitana con dos niños. ${ }^{17}$ La escultura resultante, que todavía se conserva en el museo del santuario, muestra con claridad este mismo tipo humano. En este mismo sentido apuntan las xilografías de la edición de 1552 de la Cosmographia universalis de Sebastián Münster, en la que aparece una familia y unos adivinadores de etnia gitana y L'egyptienne de François Desprez (París, 1562), esta última frecuentemente citada por la historiografía. En España, a mediados del siglo XVI, comprobamos que este era también el tipo popular de mujer gitana, como muestra la portada de la Comedia Ilamada Aurelia de Joan Timoneda, de 1564. Asimismo, resulta esclarecedor el documento de 1567 en que el obispo de Badajoz, Juan de Ribera, encargó a Morales dos cuadros de la Virgen con el Niño "vestida de gitana", que se corresponden con los conocidos cuadros del divino Morales. Del mismo modo, responde a este tipo humano la ilustracion de la Cingara orientale, publicada por Cesare Vecellio en Venecia en $1590 .^{18}$

17 CAIRATI, C.: I Da Corbetta: una bottega di intagliatori nella Milano del Cinquecento. Tesis doctoral. Milán, Università degli studi di Milano, 2014, pp. 162.

18 Sobre las Vírgenes gitanas de Morales y su origen iconográfico véase ÁVILA, A.; SÁNCHEZ-LASSA DE LOS SANTOS, A.; GARCÍA-FRÍAS CHECA, C.; RUIZ GÓMEZ, L: $E$ Divino Morales. Catálogo de la exposición celebrada en el Museo del Prado, Madrid, del 1 de octubre de 2015 al 10 de enero de 2016, pp. 86-87, 99-102, 103-105, 106-108, 186-187. Asimismo la conferencia de ÁVILA, A.:. "Una iconografía singular: la Virgen vestida de gitana", Museo del Prado, 2016, https://www.youtube.com/watch? v=DDDKEOhwmLM (consultado el 01/12/2016). SOLís RODRíGUEZ, C.: "Iconografía mariana: la Virgen vestida de Gitana con el Niño y su versión en Luis Morales", Memoria Ecclesiae, no 21, 2002, Actas del XVI Congreso de la Asociación de Archiveros de la Iglesia en España, celebrado en Zaragoza del 11 al 15 de septiembre de 2000, pp. 373-384. 
Por todo ello, podemos afirmar que a lo largo del siglo XVI fue consolidándose una imagen prototípica de la mujer gitana y esta imagen acabó imponiéndose en el siglo siguiente como un recurso iconográfico habitual a la hora de representar a la Virgen durante la huida a Egipto. El motivo era sencillo, parecía pertinente y vistoso mostrar a la Virgen en Egipto, la supuesta tierra de origen de los gitanos, vestida a la manera de las mujeres gitanas. Por ello, del mismo modo que en el caso de Sanlúcar, existen muchas otras pinturas de la Huida a Egipto en que la Virgen lleva este sombrero. Así, podemos citar como ejemplos ibéricos, las escenas del mismo asunto contenidas en De Aetatibus Mundi Imagines (1553-1573), de Francisco de Holanda. Conocemos también muestras flamencas, como el grabado inspirado en composición de Marten de Vos (ha. 1600), la Huida a Egipto de Jordaens (ha. 1655), ${ }^{19}$ el Descanso en la Huida a Egipto de Arent de Gelder (hacia 1690) ${ }^{20}$ y el mismo tema de François-Joseph Navez, muy posterior. ${ }^{21}$ Casos italianos son la Huida a Egipto de Giovanni Andrea Ansaldo del Palazzo Barberini de Roma, de los años 1620, y la Virgen con el Niño y el Bautista de Luca Cambiaso (1527-1585). ${ }^{22}$

En este último ejemplo el sombrero no es exactamente el mismo que hemos visto hasta ahora, aunque sí tiene el ala ancha y el característico encintado. De hecho podemos encontrar numerosas variantes del sombrero: colocado directamente sobre el pelo, indirectamente sobre una toca o una cofia, con el ala gruesa o delgada, plana o curva, con copa o sin ella, con visera, con barbiquejo o con una cinta para sujetarlo a la barbilla, con forma cónica, etc. Además, al tratarse de un sombrero de viaje o de peregrino, podemos verlo en numerosas obras de arte que no representan

\footnotetext{
19 En el Museo de Gante.

20 En el Museo de Bellas Artes de Boston.

21 En la Iglesia de San Pedro de Gante.

22 En la Burghley House de Peterborough.
}

la Huida a Egipto, aunque muestren personajes errantes que están de paso o recién llegados a un lugar. Así, lo vemos en el Nacimiento del Bautista de Jerónimo Cósida (de entre 1574 y 1585), ${ }^{23}$ en una de las mujeres que visitan a la recién parida Santa Isabel. También lo tenemos en la Visitación de Rubens del tríptico del Descendimiento de la catedral de Amberes (h. 1612) o en los cobres flamencos del XVII de la parroquia de Nuestra Señora de Egipto de Bogotá, donde el sombrero de ala ancha y cintas aparece en dos escenas, que ilustran a la Virgen y San José inscribiéndose en el censo y buscando posada, respectivamente. Un ejemplo muy temprano en España del uso de este sombrero en personajes errantes lo encontramos en Andalucía, en las pinturas murales del zócalo de la sala capitular del monasterio de San Isidoro del Campo, en Santiponce, fechables en la segunda mitad del siglo XV. En ellas, un mensajero abandona el scriptorium de San Jerónimo ataviado con este sombrero. En Portugal lo hallamos en la Genealogía de los Reyes de Antonio de Holanda (h. 1530 y 1534), en la escena de Santa Isabel de Portugal llegando a Santiago de Compostela, junto al conocido sombrero de peregrino decorado con la concha de igual nombre.Pero también encontramos este sombrero en escenas no religiosas, de género campesino o pastoril, ${ }^{24}$ como en la pintada por Caesar Boëtius van Everdingen (h. 1645-1650) del Rijksmuseum de Ámsterdam o en pinturas mitológicas camufladas en escenas de género, como en Vertumno y Pomona de Aert de Gelder, en la Galería Nacional de Praga. Otros ejemplos reseñables son la Historia de San Pedro con Safira y Ananías del Museo del Greco de Toledo de Juan Correa de Vivar, de mediados del XVI, los Actores de la Comedia del Arte del Museo John and Mable Ringling de Florida o el dibujo de Niccolò dell'Abbate (ha. 15121571) que representa a Moisés salvado de las aguas del Louvre.

23 En el Museo de Zaragoza.

24 En el siglo XVIII fue muy popular entre la aristocracia francesa un sombrero similar, llamado sombrero de pastora o bergère. 


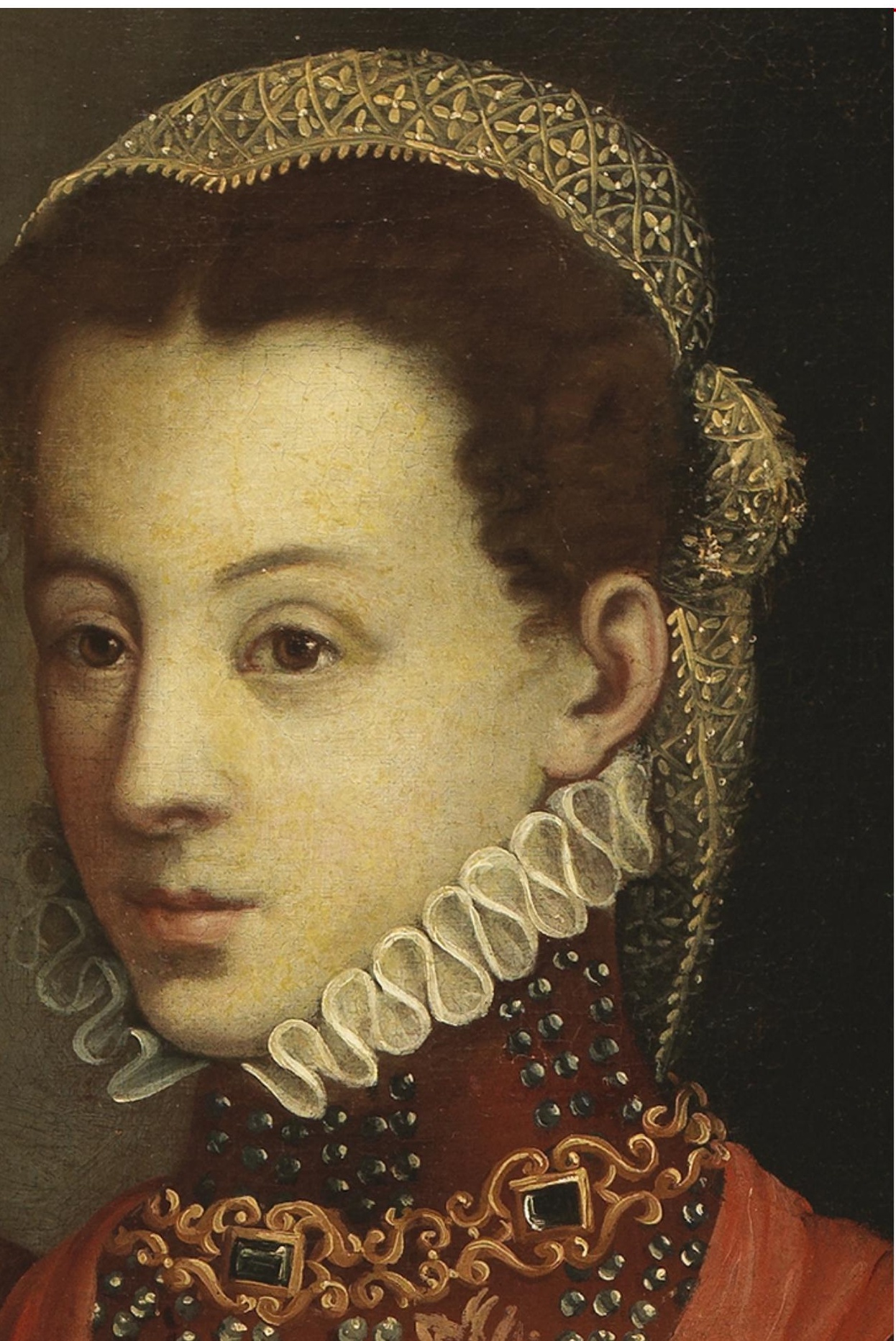

Fig. 3: Isabel de Portugal (detalle del rostro), anónimo, siglo XVI. @ Museo Nacional del Prado

Pero volviendo al caso español de las vírgenes gitanas de Luis de Morales, siguiendo la hipótesis formulada en 2007 por Isabel Mateo Gómez, hay que decir que este modelo pictórico no fue una creación del divino Morales, sino que se basa en una obra original perdida. ${ }^{25}$ La opinión de Isabel Mateo es que el prototipo de estas vírgenes fue un retrato de la emperatriz Isabel de Portugal con su hijo y heredero, el príncipe Felipe, en brazos. La hipótesis se basa en que los rasgos de la Emperatriz aparecen en una de las numerosas versiones de la Virgen del sombrero. Se trata de la conservada en una colección privada de Madrid, que salió a subasta en Londres en $2005 .{ }^{26}$ En efecto, la identificación del semblante de la Emperatriz y del príncipe Felipe niño es acertada.

Doña Isabel de Avís (1503-1539) era hija del rey Manuel I de Portugal y de la infanta María de Aragón (1482-1517), hija de los Reyes Católicos. Infanta de Portugal por nacimiento, se convirtió en reina de España al casarse con su primo Carlos I, así como emperatriz del Sacro Imperio Romano Germánico y demás títulos de los austrias españoles. Aunque conservamos bastantes retratos de Doña Isabel realizados en vida, la imagen de la Emperatriz más conocida deriva del retrato póstumo que Tiziano pintó en 1548, nueve años después de su muerte. Del modelo fijado por esta pintura conservada en el Museo del Prado, proceden otros retratos muy conocidos, como los realizados por los Leoni en mármol y en bronce, así como en forma de medallas y camafeos. Sin embargo, todas estas obras res-

25 MATEO GÓMEZ, I.: "Flandes, Portugal y Toledo...", pp. 14-15, 19-21.

26 Fue subastada el 8 de julio de 2005 en la Sala Christie's de Londres. Véase en http://web.archive.org/web/20160826065209/http://www.invaluable.com/auctionlot/luis-de-morales,-el-divino-badajoz-c.-1520-15-17-c-3fh86nycq7 (consultado el 29/12/2016) 
ponden a la imagen póstuma de la Emperatriz fijada por el pintor véneto, bastante idealizada e hierática. No obstante, conservamos otros retratos de Isabel de Portugal realizados en vida o basados en otros pintados mientras vivía. Entre ellos, debemos prestar atención a los conservados en Cerreto Guidi, ${ }^{27}$ en la Galería Nacional de Parma, en el Museo Nacional de Arte Antiguo de Lisboa (atribuido a Jos von Cleve), ${ }^{28}$ en colección particular (del taller de Vermeyen), en el Museo Nacional de Poznan (de William Scrots), en el Museo António Parreiras de Brasil, así como en el Museo del Prado (fig. 3) ${ }^{29}$ y en el Palacio Real de Riofrío (ambos anónimos). ${ }^{30} \mathrm{Si}$ centramos nuestra atención en estos retratos, seremos capaces de formarnos una idea más exacta de la imagen de la Emperatriz anterior a la labor de Tiziano y, sobre todo, de imaginarla con un rostro más vivo y expresivo. En cualquiera de los casos, la mayoría de los retratos de Isabel de Portugal, tanto los realizados en vida como los póstumos, tienen una serie de rasgos

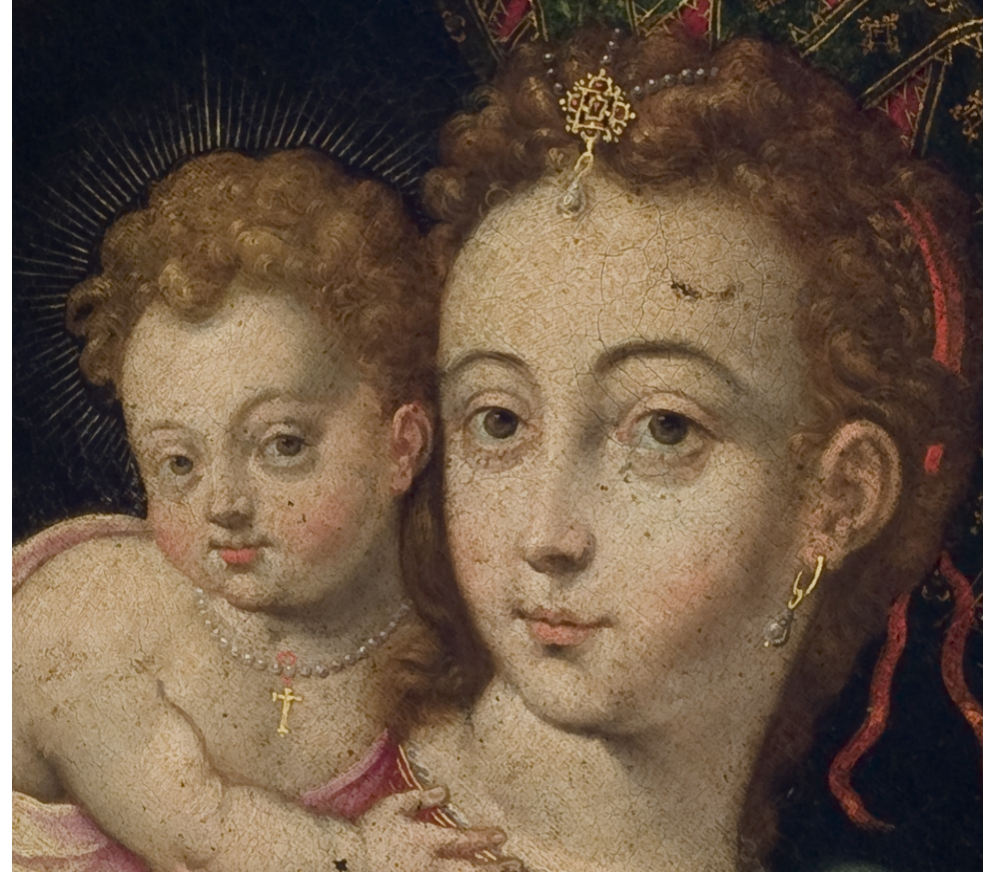

Fig. 4: Detalle de la Virgen con el Niño (foto girada). @ Fundación Casa Medina Sidonia

comunes, que son la tez pálida, el cabello pelirrojo, los ojos claros, quizá glaucos, almendrados, algo saltones y ligeramente rasgados, las cejas despejadas y arqueadas, la nariz alargada y estrecha y la boca pequeña. Asimismo, es notable el parecido que a través de los retratos se percibe entre la Emperatriz y su hermana, la infanta Beatriz de Portugal (1504-1538), que fue duquesa de Saboya por matrimonio, así como con su hermana de padre María de Portugal, duquesa de Viseu (1521-1577). En resumen, más allá de las convenciones habituales en la representación de los rostros, de la idealización casi consustancial a cualquier retrato de la época y de las

27 En Museo Storico della Caccia e del Territorio, atribuido al Maestro de Santa Auta.

28 http://web.archive.org/web/20161229191912/https://commons.wikimedia.org/wiki/Fi le:Isabel_de_Portugal_y_Aragón.jpg (consultado el 29/12/2016).

29 Depositado en el Tribunal Supremo de Justicia, Madrid.

30 Sobre los retratos de la Emperatriz véase GRAÇA MOURA, V.: "Retratos de Isabel. Imagens de uma Imperatriz", Oceanos, no 3, 1990. GRAÇA MOURA, V.: Retratos de Isabel e outras tentativas. Lisboa, Quetzal, 1994. REDONDO CANTERA, M.a J.: "La contribución de Isabel de Portugal al coleccionismo de pintura imperial", en Museo Imperial. El coleccionismo artístico de los Austrias en el siglo XVI. CHECA CREMADES, F. (Dir.), Madrid, Fernando Villaverde, 2013, pp. 121-145. diferencias de estilo existentes entre pintores, es relativamente sencillo mirar una obra y reconocer o no en ella los rasgos de la Emperatriz.

En este sentido, si observamos de nuevo la pintura de Sanlúcar, opinamos que en el rostro de la Virgen encontramos el semblante de la Emperatriz Isabel. Es más, si pasamos a observar la cara del Niño Jesús, creemos reconocer en él el rostro del rey Felipe II, con sus cabellos y ojos claros, tez pálida, frente ancha, ojos, cejas, nariz y labios de línea muy característica en él y, especialmente, un incipiente prognatismo heredado de sus antepa- 
aderezo de la cabeza de la Virgen, lo que no parece casual. ${ }^{31}$ Por ello, podemos decir que en el lenguaje iconográfico empleado en la pintura de Sanlúcar hay una clara ambivalencia entre lo religioso y lo profano, que no existe en las Vírgenes del sombrero de Morales. Esto concuerda con la hipótesis planteada por María José Redondo Cantera en $2001^{32}$ y desplegada en sucesivas publicaciones, ${ }^{33}$ según la cual el artista Antonio de Holanda habría pintado a la Emperatriz Isabel y al Príncipe Felipe bajo la forma de una Virgen con el Niño; esto es, como un retrato a lo divino.

En efecto, se sabe que Antonio de Holanda (ha. 1480-1557), pintor oriundo de los Países Bajos, establecido y activo en Portugal, ${ }^{34}$ había pintado a Felipe II en los brazos de su madre. La la tenemos gracias a su hijo Francisco de Holanda (ca. 1517-1585), ${ }^{35}$ también pintor, que en 1572

31 También hay que apuntar que la pintura de Sanlúcar es la única de las Vírgenes del Sombrero que no lleva el Niño parcialmente metido dentro de su manto, a la manera de las mujeres peregrinas.

32 REDONDO CANTERA, M.a J.: "Artistas y otros oficios suntuarios al servicio de la Emperatriz Isabel de Portugal", actas, Il Congreso Internacional de Historia da Arte. Portugal: Encruzilhada de Culturas, das Artes e das Sensibilidades. 14-17 noviembre 2001, Oporto, Associação Portuguesa de Historiadores da Arte, 2001, pp. 657-662.

33 REDONDO CANTERA, M. a J.: "Linaje, afectos y majestad en la construcción de la imagen de la emperatriz Isabel de Portugal", en Congreso Internacional "Imagen y apariencia", Universidad de Murcia, 2009. REDONDO CANTERA, Ma.: “La contribución...”. REDONDO CANTERA, María José. "Arte y suntuosidad en torno a la emperatriz Isabel de Portugal", Ars \& Renovatio, no 1, 2013, pp. 109-147.

34 Véase DESWARTE, S.: "A mais homrrada cousa de similhante calydade que em parte alguma do mundo se posa ver", en Leitura nova de Dom Manuel I. Lisboa, 1997, pp. 8789. DESWARTE, S.: "Enlumineurs à Évora dans les anées 1530. Jan Ruysch, Antonio de Holanda, Antonio Fernandes", Ao modo da Flandes. Disponibilidade, inovaçao e mercado de arte (1415-1580): actas do congresso internacional celebrado em a reitoria da Universidade de Lisboa, (11-13 de abril de 2005), pp. 197-209.

35 Nacido en Portugal, el pintor y teórico Francisco de Holanda (ca. 1517-1585), es autor escribió a Felipe II una carta ofreciéndole sus servicios artísticos y recordándole que su padre ya había servido a los suyos, retratándoles en Toledo, así como pintando al propio Felipe en el cuello de la Emperatriz ${ }^{36}$ (en portugués, no colo da Imperatriz). ${ }^{37}$ Sobre el trabajo de Antonio de Holanda en Toledo como retratista de la familia imperial, también tenemos otros datos proporcionados por su hijo Francisco en 1571. Se trata de lo relatado en el capítulo VII de su memorial Da ciência do desenho. Según Francisco, cuando él tenía veinte años, o sea, hacia 1537, el rey Juan III de Portugal lo mandó a Italia para que dibujara las cosas notables de aque

de las siguientes obras: Livro o Álbum dos Desenhos das Antigualhas (en la Biblioteca de El Escorial); De aetatibus mundi imagines. 1545, 1547 y 1551 (Biblioteca Nacional de España), Da pintura antiga (1548), Do tirar pelo natural (1549), Da fabrica que fallece á cidade de Lisboa (1571), Da sciencia do desenho (1571) y de la citada carta a Felipe II (1572).

36 Carta del pintor Francisco de Holanda al rey Felipe II de España, 22 de enero de 1572 (en portugués). Archivo General de Simancas (en adelante AGS), Sección Estado, legajo 390, documento 87. Parece que esta carta fue publicada por primera vez, informado por Carl Justi, por Joaquim de Vasconcellos. Quatro dialogos. Da pintura Antigua. Oporto, Renascença Portugueza, 1896. Hay una reproducción facsimilar de la carta en SEGURADO, J.: Francisco d'Ollanda. Lisboa, Edições Excelcior, 1970, y una transcripción de la misma en DESWARTE, S.: "Les De Aetatibus Mundi Imagines de Francisco de Holanda", Monuments et mémoires de la Fondation Eugène Piot, tome 66, 1983, pp. 67-190, aquí véase p. 187

37 Obsérvese que la expresión no colo da Imperatriz presenta cierta ambigüedad. En portugués contemporáneo $o$ colo se usa para designar la parte alta del pecho, lo que en español llamamos el escote. También se usa colo para nombrar el cuello de una prenda, pero no para llamar a la parte del cuerpo que en español llamamos cuello, que en portugués se dice pescoço. Asimismo la expresión no colo significa "en el regazo", entendiendo regazo como una "cosa que recibe en sí a otra, dándole amparo, gozo o consuelo" (Diccionario de la Real Academia Española), no necesariamente en la falda de una persona sentada, formada entre la cintura y las rodillas. Aquí optamos por la traducción literal "en el cuello de la Emperatriz". 
país. ${ }^{38}$ Estando de viaje, pasó por Valladolid, donde visitó a la Emperatriz, encargándole esta que a su paso por Barcelona, de su parte robara un retrato a su marido, el Emperador. Asimismo, según Francisco, por entonces recibió una carta de su padre diciéndole que de ninguna manera se fuera de Barcelona sin hablar y sin besar la mano de Carlos V. De este modo, Francisco relata su entrevista con el Emperador, que se rió al oír la propuesta y se negó a ser efigiado, argumentando que ya era viejo para consentirlo. Asimismo, recordó a Francisco que nadie lo había retratado mejor que su padre, Antonio de Holanda, en Toledo, ni siquiera el mismísimo Tiziano. ${ }^{39}$ Sobre esta opinión artística del emperador, quizá exagerada por Francisco para alabar a su padre, este ya había escrito brevemente en 1549 recordando la misma opinión de Carlos V; esto es, "que mejor le había sacado al natural Antonio de Holanda en Toledo de iluminación; que Tiziano en Bolonia". ${ }^{40}$

Sylvie Deswarte ya supuso que los trabajos que Antonio de Holanda hizo para la familia imperial en Toledo debió de realizarlos a partir de febrero de 1529 , formando parte de la embajada de Álvaro Mendes de Vasconcellos. ${ }^{41}$ Lo cierto es que la corte se había instalado allí en octubre de 1528 y la profesora Redondo ha aportado que en abril de 1529, Isabel ordenaba que se pagaran 300 ducados a Antonio de Holanda, "vecino del reino de

38 Fruto de este encargo es el Livro o Álbum dos Desenhos das Antigualhas, conservado e n la Biblioteca de El Escorial. Véase OLIMPIO DOS SANTOS, R.: O Álbum das Antigualhas de Francisco de Holanda. Universidad de Juiz de Fora, 2015. Tesis doctoral.

39 DE HOLANDA, F.: Da sciencia do desenho. 1571. Edición de DE VASCONCELLOS, J.: Francisco de Hollanda. Da fabrica que fallece á cidade de Lisboa. Da sciencia do desenho. Oporto, Imprensa Portugueza, 1879, parte II, pp. 20-22.

40 DE HOLANDA, F. : Do tirar pelo natural. 1549. Véase la traducción de realizada por Manuel Denís en 1563: Del sacar por el natural. Ed. de John B. Bury, Madrid, Akal, 2008, p. 14,90

41 DESWARTE, S.: “A mais homrrada cousa...", p. 88.
Portugal", por "ciertas imágenes y pinturas que me ha dado". ${ }^{42}$ De hecho, años después en la recámara de la Emperatriz se consignaban "dos retablos guarnecidos de plata que vinieron de Portugal que hizo Antonio de Olanda"..$^{43}$ Por ello, si damos por buena la fecha de 1529, la emperatriz contaría en el retrato de Sanlúcar con unos veintiséis años, mientras que el príncipe Felipe no llegaría a los dos, lo que concordaría con la edad que aparentan tener los efigiados.

Por entonces, los retratos a lo divino ya eran un género que contaba con cierta trayectoria en gran parte de Europa y la península ibérica no era una excepción. Ampliamente conocido es el caso de la Virgen con el Niño y ángeles de Jean Fouquet (1450) del Museo de Bellas Artes de Amberes, que tradicionalmente se identifica como retrato de Agnès Sorel, favorita del rey Carlos VII de Francia. Asimismo es paradigmático de este género el retrato del rey Francisco I de Francia como San Juan Bautista, pintado por Jean Clouet en $1518^{44}$ o el de Ana de Bergh, marquesa de Veere, bajo la apariencia de la Virgen con el Niño, realizado por Mabuse y conocido por una copia del Metropolitan de Nueva York (h. 1522). Dentro de la casa de Habsburgo y de las casas reales castellana y portuguesa, hay que citar varios ejemplos: la familia de Maximiliano I representada como la Parentela de Cleofás (del Kunsthistorisches Museum de Viena), ${ }^{45}$ el retrato d e Isabel la Católica como la Magdalena (de la Galería Nacional de

42 AGS, Cámara de Castilla, libro 318-2, f. 17. REDONDO CANTERA, M. a J.: "La contribución...", p. 125.

43 AGS, Estado, leg. 45, f. 246. REDONDO CANTERA, M.a J.: “La contribución...”, p. 138.

44 Véase la obra en:

http://web.archive.org/web/20161229194809/http://www.thearttribune.com/spip.ph p?page=docbig\&id_document=2260 (consultado el 29/12/2016).

45 Obra de Bernhard Strigel (1460-1528) en que se representan tres generaciones de la casa de Austria, incluido un retrato juvenil de Carlos V. 
Londres), ${ }^{46}$ Carlos $V$ como San Sebastián (de la galería Caylus de Madrid) y Catalina de Austria (hermana de Carlos V) como Santa Catalina, conservada en El Prado. Salvando las distancias, todos estos retratos a lo divino, tienen su precedente en la Antigüedad, en las representaciones de reyes mesopotámicos, faraones egipcios, emperadores y otros personajes divinizados, como Antinoo.

En cuanto a los retratos con sombrero de ala ancha, en el entorno familiar imperial se conocen varios ejemplos. En este sentido, véanse los bustos de terracota de Carlos V del Museo Gruuthuse de Brujas y del Museo de Bellas Artes de Gante, así como los retratos pictóricos realizados por Hans Maler de las reinas María y Ana de Hungría, que están en la Society of Antiquaries de Londres y en colección particular respectivamente. Estos dos últimos retratos, de la cuñada y de la concuñada de Isabel de Portugal ${ }^{47}$ están fechados en 1520 , por lo que serían prácticamente contemporáneos al retrato de la Emperatriz y del Príncipe que Antonio de Holanda realizó en 1529.

Por su parte, la representación de la Virgen con el Niño al cuello, dentro o fuera de tondos, ya era de sobra conocida dentro del arte italiano de la segunda mitad del XV y del primer tercio del XVI. Son extraordinariamente famosos los ejemplos de la mano de Andrea Mantegna, Fra Filippo Lippi, Ghiberti, Bellini, Botticelli o Rafael, entre otros. En el caso de las Vírgenes gitanas de Morales, se ha sugerido el influjo concreto de la Madonna del Granduca (ha. 1504) y de la Piccola Madonna Cowper de Rafael (ha. 1505), lo que por lo tanto también es aplicable a la pintura de Sanlúcar. Asimismo

46 FLOR, P.: "Un retrato desconocido de Isabel la Católica", Archivo Español de Arte, tomo 86, no 341, 2013, pp. 1-14.

47 La reina María de Hungría (1505-1558) era hermana de Carlos V, mientras que la reina Ana (1503-1547) era la esposa del emperador Fernando I (1503-1564), su hermano. se ha propuesto como posible fuente, un grabado de Marcantonio Raimondi de hacia 1520 conocido como la Madonna del Catino, basado en una composición de autoría incierta del círculo de Rafael. ${ }^{48}$ Además, en la península ibérica debieron de gozar de cierta popularidad los relieves de barro esmaltado con dicha iconografía del taller de Andrea della Robbia Así parecen indicarlo, entre otros, los ejemplos conservados en la catedral de Sevilla y el que estaba sobre la fachada de la iglesia del monasterio de Madre de Dios de Lisboa, como puede observarse en la pintura del Maestro de Santa Auta, sobre el traslado de las reliquias de dicha santa. ${ }^{49}$ Asimismo, en el contexto del arte flamenco de los años en que Holanda realizó el retrato de Isabel y Felipe, encontramos bastantes obras similares, como la Virgen con el Niño de Mabuse, de El Prado, fechada por los mismos años que el retrato, o la atribuida a Guillaume Benson del Museo de Bellas Artes de Sevilla, entre otras muchas.

Sobre Antonio de Holanda, autor del retrato de Felipe II en los brazos de la Emperatriz, que la pintura de la Fundación Medina Sidonia parece seguir muy de cerca, tenemos que decir que no es un pintor demasiado conocido por el gran público, aunque sí entre los especialistas, sobre todo en su faceta de miniaturista. Ampliamente conocida es su Genealogía de los reyes de Portugal, ${ }^{50}$ un códice realizado entre 1530 y 1534 y conservado en Londres, en la Biblioteca Británica. ${ }^{51}$ El libro, compuesto por 13 folios, fue encargado por el infante don Fernando de Portugal (1507-1534), hermano

48 ÁVILA, A.; SÁNCHEZ-LASSA DE LOS SANTOS, A.; GARCÍA-FRÍAS CHECA, C.; RUIZ GÓMEZ, L.: El Divino Morales, op. cit., p. 99.

49 Conservado actualmente en el Museu Nacional de Arte Antiga.

50 http://web.archive.org/web/20161229193405/https://commons.wikimedia.org/wiki/Fi le:Genealogia_dos_Reis_de_Portugal_-_Tavoa_Primeira_dos_Reys__Tronco_do_Conde_Dom_Anrique.jpg (consultado el 29/12/2016).

51 Bajo la signatura "Additional MS 12531". 
de la emperatriz Isabel, a Antonio de Holanda, cuyo taller trabajó frecuentemente para la Casa real portuguesa en este tipo de encargos. Se trata de una obra realizada en colaboración, pues Holanda se encargó de dibujar en Portugal los trece folios que tiene el códice, mientras que Simón Bening dio color en Brujas a cinco de ellos. El resto fueron iluminados por el propio Holanda, salvo la última hoja que quedó sin colorear a la muerte del infante comitente. Esta Genealogía es un obra exquisita compuesta por escudos, vistas de ciudades, registros historiados, elaboradas orlas y sobre todo complejos árboles genealógicos, cargados con diminutos retratos idealizados de los miembros de la casa real portuguesa. Estos minúsculos dibujos nos hablan del extremado virtuosismo técnico de Holanda, aparentemente formado en su país de origen, dentro del preciosismo de tradición flamenca.

La historiografía considera que su arte está emparentado con la escuela de Gante y Brujas, dentro de la estela de Hugo van der Goes (ha. 1440-1482). Documentalmente hablando, se desconoce su lugar y fecha de nacimiento, dónde realizó su formación artística, así como cuándo se estableció en Portugal. Sin embargo, los historiadores han hecho varias propuestas al respecto. Antonio de Holanda pudo nacer en Amberes hacia 1480, pues en los libros del gremio de pintores de dicha ciudad se registra en el siglo XV una familia de dicho apellido. ${ }^{52}$ A tenor de su estilo, se ha señalado que pudo formarse en el taller de Alexandre Bening († Gante, 1512), dentro del ambiente pictórico gantés-brujense, derivado del arte de Hugo van der Goes. No en vano Bening había casado con Catheleyne van der Goes, hermana o sobrina de Hugo.

52 PINCHART, A.: "Tableaux et sculptures de Marie" Tableaux et sculptures de Marie d'Autriche, Reine douairière de Hongrie (1558)", Revue Universelle des Arts, tomo 3, Bruselas, 1856, p. 135
En Portugal, hacia 1500, un grupo de pintores flamencos procedente de este contexto artístico, entre los cuales estaba Francisco Henriques, trabajó en una serie de pinturas destinadas a la catedral y la iglesia de San Francisco de Évora. En este medio artístico gantés-brujense la miniatura ocupaba un importante lugar y era frecuente que en ella se usaran las mismas fórmulas que en la pintura de mayor formato. Se desconoce si Holanda llegó a Portugal dentro de este grupo de artistas que trabajaron en Évora o si lo hizo por iniciativa propia. Lo cierto es que el gusto de la familia real portuguesa por la miniatura gantés-brujense era conocido y Holanda bien pudo marchar a Portugal para fundar allí su propio taller. En este sentido, la primera obra que se le atribuye es el Misal polifónico de Viena, fechado en 1500, realizado con motivo de la boda entre Manuel I de Portugal y María de Aragón y que fue regalo del cuñado de esta, Felipe el Hermoso. Pero quizá el detonante que desencadenó el establecimiento de Antonio de Holanda en Portugal fueron las grandes empresas editoriales que inició el rey don Manuel: los fueros nuevos, las crónicas, los armoriales y la Leitura Nova, una lujosa recopilación de importantes documentos del archivo real, dirigida por el iluminador Álvaro Pires. Precisamente se atribuye a Holanda el frontispicio de una de sus partes, el libro llamado Místicos, datado en 1511 y donde se aprecia la técnica de punteado. Esta manera de dibujar de hecho fue inventada por el propio Antonio de Holanda, como reivindicó en sus escritos su hijo Francisco, recordando que su padre la había usado mucho antes que Giulio Clovio (1498-1578), llamado "el Miguel Ángel de la miniatura".

La carrera pictórica de Antonio de Holanda en Portugal corrió en paralelo a su carrera heráldica en la corte real portuguesa, como oficial de armas. En 1518 fue nombrado persevante de armas y hacia 1521 diseñó el cetro del rey Juan III. ${ }^{53}$ Posiblemente su estancia en Toledo en 1529, en la cual realizó

53 DE HOLANDA, F.: Da sciencia do desenho. 1571, fol. 40 ํo. Véase la edición de DE 
el retrato de la Emperatriz y el Príncipe, se debió a su calidad de persevante, dentro de la citada embajada de Álvaro Mendes de Vasconcellos, de febrero de ese año. En 1534 seguía siendo persevante, pero promocionó a la muerte de Pero de Évora, asumiendo los cargos de "escrivão da nobleza" y de "Rei de Armas Algarve", que ocupó desde 1538 hasta 1542, para alcanzar en 1556 el cargo de "Rei de Armas Índia". Como escribano de la nobleza, Holanda tuvo asegurada una buena posición económica, derivada del alto coste de las cartas de blasones, valoradas en 1000 reales cada una. Asimismo las circunstancias familiares de Antonio de Holanda reforzaron su posición. En este sentido hay que decir que su esposa y madre de sus hijos (Francisco, Miguel, Juan, Jerónimo y María) era familiar del cosmógrafo Lopo Homen, quien dirigió la confección del famoso Atlas Miller (ha. 1519). De hecho parece que Holanda participó en este atlas representando animales exóticos. En base a esto se ha supuesto que Antonio fue el autor del boceto que sirvió a Durero para la creación de su famoso grabado de un Rinoceronte, cuyo dibujo (de 1515) se encuentra en el Museo Británico y que fue la imagen de este animal más extendida por Europa hasta finales del siglo XVIII. ${ }^{54}$ Dentro de esta situación personal y laboral en la corte portuguesa, Antonio de Holanda emprendió la iluminación de muchas obras, como el Testamento de Rui de Pina (1515), el Libro de horas de Manuel I (1517), la Crónica de Don Alfonso Henriques de Duarte Galvão (ha. 1520), la Crónica de Don Juan I de Fernão Lopes (ha. 1530) y la Genealogía del conde da Feira (1534). Asimismo, participó en otras empresas en colaboración con otros iluminadores. ${ }^{55}$

VASCONCELLOS, J.: “Francisco de Hollanda. Da fabrica...", parte II, p. 11.

54 MARKL, D.: História da Arte portuguesa. Vol. 3. Lisboa. 1995, pp. 417-418. Véase también DE ANDRADE MARTINS, R.: "O rinoceronte de Dürer e suas lições para a historiografia da ciência", Filosofia e História da Biologia, São Paulo, v. 9, n. 2. 2014, pp. 199-238.

55 Para todos estos y otros muchos aspectos de la vida de Antonio de Holanda, véase
En la plenitud de estos años se sitúa también la elaboración de su obra maestra, la mencionada Genealogía de los reyes de Portugal, un códice realizado entre 1530 y 1534, que quedó inacabado a la muerte de su comitente. A falta de un catálogo de obras seguro, este códice resulta crucial para intentar establecer el estilo de este pintor luso flamenco. En este sentido, podemos decir que la pintura de Sanlúcar parece encajar con el estilo desplegado por Antonio de Holanda en la Genealogía de los reyes. Más allá de las convenciones del gótico tardío, todavía presentes en el códice, ambas obras coinciden especialmente en la morfología de las manos, en la suntuosidad de la indumentaria y en la gran expresividad y vivacidad de los rostros. Asimismo, el tratamiento de los pliegues que se observa en la ropa del Niño Jesús de Sanlúcar es similar al usado por Holanda en varias figura de su Genealogía, como en las mangas del retrato de Juana de Portugal. ${ }^{56}$ Lo evidente es que la obra de Sanlúcar muestra un virtuosismo en el detalle propio de la mano hábil de un miniaturista. Del mismo modo, el tipo femenino de mujer con sombrero y que lleva a su hijo en su manto, también fue plasmado por Holanda en la "Matanza de los Inocentes", miniatura integrada en las Horas de la Virgen. ${ }^{57}$ Además, la confrontación de la obra de la Fundación Medina Sidonia con el Cristo atado a la columna y con el Ecce Homo, atribuidos a Holanda por Isabel Mateo Gómez, nos devuelve claras coincidencias estilísticas. De hecho, podría formularse la hipótesis de que estas dos tablas pintadas al óleo, de formato pequeño y estrecho $(81 \times 24 \mathrm{~cm}$.) pudieron formar parte de alguno de los retablos en forma de tríptico que Holanda pudo hacer o

DESWARTE, S. “A mais homrrada cousa...”, pp. 45-49, 87-88.

56 http://web.archive.org/web/20150615075231/http://commons.wikimedia.org/wiki/Fil e:D._Joana_de_Portugal,_Rainha_de_Castela_-

The Portuguese Genealogy_(Genealogia dos Reis de Portugal).png (consultado el 29/12/2016).

57 En el Museo Nacional de Arte Antigua de Lisboa, fol. 109 ํo. 
vender a la familia imperial. ${ }^{58}$ No en vano, el personaje admonitorio que contiene el Ecce Homo (fig. 6) podría ser un retrato y tiene cierto parecido con el Emperador, cuya imagen anterior a Tiziano varía mucho de un retrato a otro. Aunque este es un terreno resbaladizo que preferimos no explorar.

Volviendo a la pintura de Sanlúcar, hay que preguntarse si los inventarios reales revelan la presencia del retrato realizado por Holanda. ${ }^{59}$ De momento esta cuestión no tiene una respuesta satisfactoria, sin embargo, hay que dar algunos datos y apuntar algunas posibilidades. Sabemos que la Emperatriz tenía "un retablo de Nuestra Señora" y "Nuestra Señora en otra cajica". ${ }^{60}$ También se ha publicado que la Emperatriz dispuso en su testamento de 1539 que las piezas de su oratorio se destinaran a sus hijas, las infantas doña A Juana y doña María, ${ }^{61}$ aunque en 1555 dichas piezas fueron compradas por su hermano Felipe II y reintegradas en la

Fig. 6: Ecce Homo, atribuido a Antonio de Holanda, Galería Bernat (Barcelona)

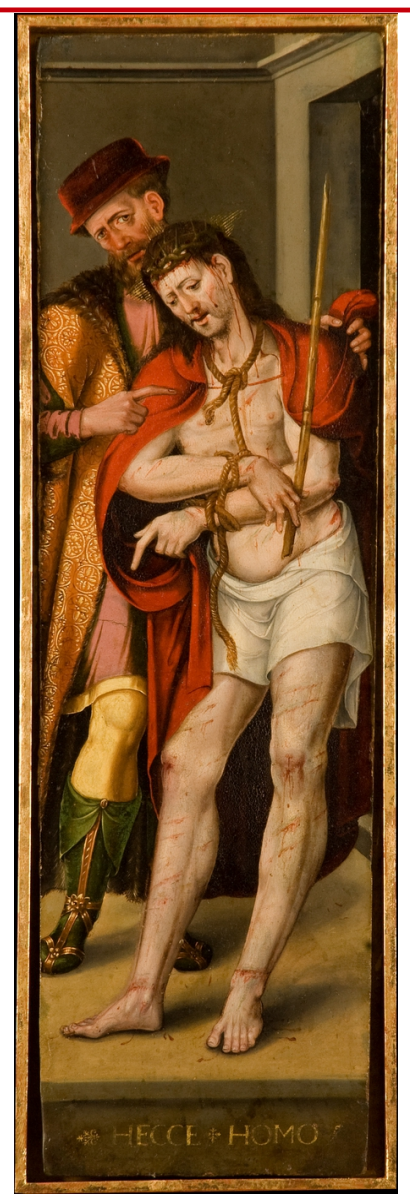

colección real. ${ }^{62}$ A pesar de ello, algunas obras religiosas fueron vendidas en la almoneda de los bienes de la Emperatriz. Entre ellas cuatro pinturas de la Virgen con el Niño, llamando nuestra atención una vestida de "azul y rojo", comprada por Rodrigo de Portillo, y otra vestida de azul y de formato circular, adquirida por Pedro de la Torre. $^{63}$ No obstante, mas allá de las coincidencias parciales en la descripción, echamos en falta la alusión en los inventarios al sombrero que lleva la Virgen, que tendría que haber llamado la atención del redactor del inventario, por lo que es difícil saber si se trataba de esta misma obra. Del mismo modo, conocemos que tras la muerte de la Emperatriz, en la cabecera de la cama del príncipe Felipe se colgó el retablo que Enrique III de Nassau (1483-1538) había regalado a la Emperatriz y que contenía las obras aludidas anteriormente; esto es, el "retablo de Nuestra Señora" y "Nuestra Señora en otra cajica". ${ }^{64}$ También interesa decir que Carlos $V$ durante su retiro en el Monasterio de Yuste tenía tres retratos de la Emperatriz pintados sobre pergamino que se guardaban en una bolsa de seda torcida morada, y que fueron comprados por Felipe II a la muerte de su padre. ${ }^{65}$
58 Ambas tablas son propiedad de la galería de arte Bernat. La información sobre la atribución de las tablas a Holanda por parte de Isabel Mateo Gómez ha sido facilitada al autor por la propia galería.

59 CHECA CREMADES, F. (Dir.): Los inventarios de Carlos $V$ y la familia imperial. Madrid, Fernando Villaverde Ediciones, 2010. 3 tomos.

60 AGS, CSR, leg. 67, f. 206. CHECA CREMADES, F. (2010). "Los inventarios...", tomo II, p. 2206. REDONDO CANTERA, M.a J.: “La contribución...”, pp. 136-137.

61 AGS. Patronato Real, leg. 30, fol. 510. REDONDO CANTERA, M.a J.: La contribución..., p. 137.
62 CHECA CREMADES, F. (Dir.): Los inventarios de Carlos $V$ y la familia imperial, Tomo II, Madrid, Fernando Villaverde Ediciones, 2010, pp. 2207.

63 REDONDO CANTERA, M.a J.: “La contribución...”, pp. 141-142.

64 Ibid., pp. 136-137.

65 MARTín GONZÁLEZ, J. J.: "El palacio de Carlos V en Yuste", Archivo Español de Arte tomo 24, no 94, 1951, pp. 125-140. CHECA CREMADES, F. (Dir.): Los inventarios de Carlos $V$ y la familia imperial, Tomo I, Madrid, Fernando Villaverde Ediciones, 2010, p. 125. 
Asimismo, sabemos que Carlos $V$ se quedó con una "ymagen muy linda de la Virgen", que había sido muy apreciada por la Emperatriz, acompañándola en sus últimos días y que colgaba sobre la cabecera del Emperador cuando este murió en Yuste en 1558 y que Felipe II compró a su muerte. ${ }^{66}$ Nos preguntamos si la pintura de la Virgen que acompañó a la Emperatriz en sus últimos momentos, la que se colgó a su muerte en la cabecera del príncipe Felipe y la que presidió el lecho de muerte de Carlos $\mathrm{V}$ pudo ser la misma pintura. Parece difícil determinarlo.

De igual manera, desconocemos cómo pudo llegar el retrato de la Emperatriz y el Príncipe a la colección Medina Sidonia, pues las posibilidades son numerosas y las certezas nulas. La relación de parentesco de los Medina Sidonia con la familia imperial es conocida. La duquesa doña Ana de Aragón y Gurrea, sucesiva consorte del V y del VI duque de Medina Sidonia, era prima tanto de Carlos $V$, como de su esposa Isabel, pues tenían el mismo abuelo: el rey Fernando el Católico. Asimismo, su marido el VI duque, don Juan de Guzmán (1502-1558), había sido el encargado de conducir a Sevilla en 1526 a Isabel de Portugal para casarse con el Emperador. ${ }^{67}$ Además, la duquesa Ana era tía de San Francisco de Borja, ${ }^{68}$ caballerizo mayor de la Emperatriz, quien visitó a la duquesa de Medina en Sanlúcar en $1553 .{ }^{69}$ Asimismo, este general de la Compañía era hermano

66 REDONDO CANTERA, M. a J.: “La contribución...”, p. 141

67 VeLÁZQUeZ-GAZTELU, J. P.: Historia Antigua de la ciudad de Sanlúcar de Barrameda escrita en el año 1760. Tomo 2, Sanlúcar de Barrameda, ASEHA, edición de 1994, p. 281.

68 Todos los duques de Medina Sidonia, a partir del noveno, son descendientes de San Francisco de Borja, pues el VIII duque de Medina se casó y tuvo su descendencia legítima con su bisnieta, doña Juana de Sandoval, hija del I duque de Lerma.

69 VELÁZQUEZ-GAZTELU, J. P.: Fundaciones de todas las iglesias, conventos y ermitas de Sanlúcar de Barrameda escrita en 1758. Sanlúcar de Barrameda, ASEHA, edición de 1995, p. 384. de Luisa de Borja y Aragón, conocida como la Santa Duquesa y criada por su tía en el palacio de Sanlúcar, hasta que casó en 1541 en Medina Sidonia con Martín de Gurrea y Aragón, conde de Ribagorza y después IV duque de Villahermosa, conocido coleccionista que sabemos compró pinturas en la almoneda de la Emperatriz. ${ }^{70}$ Igualmente, si seguimos la hipótesis de la prof. Redondo de que el retrato pudo pasar a la colección real portuguesa, existen vínculos entre esta y la casa ducal de Medina Sidonia, pues doña Luisa de Guzmán (1613-1666), hija del VIII duque, fue reina consorte y regente de Portugal, como esposa de Juan IV y madre de Alfonso VI. Todos estos vínculos familiares y eventualidades, pudieron suscitar regalos familiares y diplomáticos, ${ }^{71}$ sin olvidar la posibilidad de que los duques adquirieran el retrato por herencia, como sucedió con una colgadura que el Emperador usó en Yuste, comprada en su almoneda por el duque de Béjar y que heredó su descendiente, doña Leonor de Sotomayor y Zúñiga, condesa consorte de Niebla, quien la cedió a la Iglesia Mayor de Sanlúcar, donde adornaba la capilla mayor durante la Semana Santa. ${ }^{72}$

Lo cierto es que en los inventarios de la casa de Medina Sidonia consultados, no se ha encontrado por el momento rastro de la pintura. Además, todas estas posibilidades se multiplican si tenemos en cuenta que la casa de Medina Sidonia se incorporó a lo largo de la historia a otros importantes mayorazgos nobiliarios, como son las casas de Villafranca del Bierzo, los Vélez y Montalto-Paternò. Un aspecto curioso es que dentro de la tradición oral de la casa de Medina Sidonia, al menos en tiempos de la XXI duquesa (1936-2008), ha permanecido la creencia de que esta pintura

70 REDONDO CANTERA, M.a J.: “La contribución...”, p. 143.

71 La naturaleza privada de la pintura de Sanlúcar hace que nos parezca más probable que la obra llegara a los Medina Sidonia como un regalo familiar, no diplomático, aunque ambos tipos de presente eran con frecuencia la misma cosa.

72 VELÁZQUEZ-GAZTELU, J. P.: “Fundaciones...”, p. 96-97. 
es un retrato a lo divino de doña Ana de Silva y Mendoza (1560-1610), consorte del VII duque de Medina Sidonia, con su hijo el conde de Niebla en brazos. Este error en cuanto a la identidad de los retratados, podría derivar del acomodo de la verdad histórica a la retórica propia de la casa ducal. ${ }^{73}$ En este sentido, hay que decir que dentro del linaje existe al menos otro ejemplo de retrato apócrifo. Se trata del supuesto retrato de Guzmán el Bueno con su hijo, ampliamente difundido a través de estampas, que en realidad se trata de una copia del taller de Van Dyck del retrato del conde de Arundel con su nieto el duque de Norfolk. ${ }^{74}$ Un caso similar al de la Virgen con el Niño de Sanlúcar, en que un retrato se convirtió en el modelo de una pintura religiosa, obviándose la identidad del personaje retratado, lo tenemos en la efigie de Laura Dianti, amante de Alfonso de Este, III duque de Ferrara, pintada por Tiziano, que fue ampliamente difundida por una estampa de Aegidius Sadeler (1570-1629) y que acabó convirtiéndose en el modelo de una Salomé.

73 Existe un pago en el archivo de la Fundación Medina Sidonia, que se ha venido identificando erróneamente como el pago por la pintura objeto de este estudio. Se trata de una carta de pago a Juan de Campaña, hijo de Pedro de Campaña, por valor de 20 ducados. Véase el Archivo General de la Fundación Casa de Medina Sidonia (AGFCMS), legajo 2656. Tesorería de la casa de su Excelencia. Cuentas de Tesorero Alonso Ramírez Beltrán. Años 1579-1580 y 1581. Tomo 59. Libro sin foliar. "Alonso Ramírez Beltran mi tesorero dad de los maravedies de vuestro cargo a Juan de Campania pintor veynte ducados por un retrato de mi señora ta duquesa de Béjar [tachado aparentemente por el propio escribano] que Dios tiene sobre tabla y guarnecido con su muldura y dorada que dio en mi camara y tomad su carta de pago, fecho en dos de mayo de I U L LXX IX años [firmado al dorso] Juan de Campaña".

74 El original de Van Dyck se conserva en Arundel Castle, en Inglaterra. La copia de taller de la colección Medina Sidonia fue donada a El Prado en 1926 por Alonso Álvarez de Toledo y Caro, conde de Niebla, hijo malogrado del XVIII duque de Medina Sidonia.
Al margen de estas tradiciones erróneas, la intimidad y el naturalismo que envuelven el retrato de la Emperatriz y del Príncipe, así como la franqueza y dulzura con que los retratados miran al espectador, bajo el artificio de tratarse de una obra piadosa, alejan esta pintura de Sanlúcar de los rígidos modelos propios del retrato de estado o de aparato, convirtiéndolo en una obra de naturaleza familiar y privada. No obstante, el retrato no está exento de una gran idealización y verdaderamente proporciona "la imagen de la continuidad dinástica de los Habsburgo en España". ${ }^{75}$

Por último, si damos por buena la hipótesis que plantea este trabajo, la aparente interdependencia entre el retrato original de Antonio de Holanda y las Vírgenes del sombrero de Morales, ahonda en la posible relación de maestría y aprendizaje entre ambos pintores, ya propuesta por Isabel Mateo Gómez ${ }^{76}$ y que ahora podría tener un nuevo elemento tangible. En este mismo sentido, hay que considerar la posible influencia del fondo negro de la pintura de Sanlúcar, o del original de Holanda, en la producción de Morales, como ya se ha apuntado en el caso de los óleos sobre pizarra, que representan a Cristo con la cruz a cuestas, de Sebastiano del Piombo; ${ }^{77}$ modelo que, como el retrato de la Emperatriz, también fue usado repetidamente por Morales para las pinturas de devoción salidas de su taller. $^{78}$

75 REDONDO CANTERA, M.a J.: “La contribución...”, p. 126.

76 MATEO GÓMEZ, I.: op. cit., pp. 14, 15, 19, 21.

77 En el Hermitage y el Prado, respectivamente.

78 ÁVILA, A.; SÁNCHEZ-LASSA DE LOS SANTOS, A.; GARCÍA-FRÍAS CHECA, C.; RUIZ GÓMEZ, L.: El Divino Morales, op. cit., pp. 56, 57, 190-197. Asimismo, existe un sugerente parecido entre la pintura de Sanlúcar y la Madonna della Purità de la basílica mayor de San Pablo de Nápoles, obra de Morales. Ambas son Vírgenes con el Niño al cuello y están representadas en un tondo redondo inscrito en un cuadrado y flanqueado por cuatro querubines protectores con las alas abiertas. Bien es cierto que en el caso napolitano no se trata de un marco pintado, por lo que podría ser un añadido ajeno a 
Por todo lo anterior y en resumen, este trabajo propone que la pintura de la Fundación Casa de Medina Sidonia es un retrato del príncipe Felipe niño en el cuello de su madre, la Emperatriz Isabel de Portugal. Es la obra más cercana que conocemos al original que Antonio de Holanda pintó en Toledo hacia 1529. Se trata, pues, de un retrato a lo divino de carácter privado, que dentro de ambas categorías podemos considerar bastante temprano en el contexto español. Se trataría, por tanto, de una nueva efigie de la Emperatriz, anterior a la imagen icónica creada por Tiziano. Asimismo sería el retrato más antiguo que tenemos de Felipe II y el único retrato infantil que se conocería de dicho monarca. Sería, pues, la obra más cercana al original perdido que sirvió a Luis de Morales para la creación de sus famosas Vírgenes gitanas, uno de los modelos pictóricos religiosos más populares del Siglo de Oro español, así como de una pieza clave para intentar iniciar un catálogo de pinturas de caballete de Antonio de Holanda, que vaya más allá de sus conocidas miniaturas.

Para finalizar, de confirmarse que la obra de la Fundación Medina Sidonia sigue fielmente la obra perdida de Holanda, realizada en 1529, cabría preguntarse si el retrato original fue el primer caso de la historia del arte ibérico en que se representó a la Virgen durante la Huida a Egipto "vestida de gitana", así como qué lugar ocupa en este mismo sentido dentro del contexto europeo. La confirmación o la negación definitiva de todos estos aspectos planteados, parece que no será posible hasta que aparezcan datos documentales fiables y se realice un completo estudio técnico de la obra $^{79}$ pues hay que advertir que el examen de la pintura ha sido

la obra original de Morales. En cualquier caso, la devoción a la Purità también convirtió esta obra de Morales en un icono religioso ampliamente repetido en Italia y lo cierto es que, con las vírgenes del sombrero de Morales y las múltiples copias de su Madonna della Purità, nos encontramos ante dos casos bastante excepcionales en la Historia del Arte español de creación de iconos religiosos, lo cual sin duda es digno de reseña.

79 Hemos podido estudiar físicamente la obra con la ayuda de María Luisa Millán Salgado, meramente visual. En cualquier caso, insistimos en que parece que estamos ante la obra conocida más cercana al original perdido de Antonio de Holanda. ${ }^{80}$ conservadora y restauradora, a quien el autor agradece con entusiasmo su imprescindible ayuda. Asimismo, en el catálogo de bienes muebles de la Fundación Casa de Medina Sidonia, existe un estudio técnico realizado por personal del Instituto Andaluz de Patrimonio Histórico (IAPH), que dice lo siguiente: "Pintura realizada en óleo sobre lienzo, cuyas medidas son $50 \times 43 \mathrm{~cm}$., sin marco y $59 \times 53 \mathrm{~cm}$. ( $h \times a)$, con marco. Presenta bastidor de tipo rectangular no original, realizado en pino, de corte longitudinal. Está compuesto por cuatro travesaños, dos horizontales y dos verticales. Sus medidas son $50 \times 43 \mathrm{~cm}$. ( $h \times a$ ), con una anchura de listones de 3,5 cm. y espesor de $2 \mathrm{~cm}$. El ensamble es a horquilla, con sistema de expansión por cuñas, que ha desaparecido. El soporte original ha sido reentelado para dar más firmeza a las fibras debilitadas de la tela de lino original. El sistema de montaje de la tela al bastidor es por medio de tachuelas sobre el perímetro del bastidor. La capa de preparación es una mezcla de sulfato de cal más un aglutinante. La imprimación es de color blanca y aplicada en la totalidad de la superficie del soporte. Es sensible al agua debido a su poca adherencia al soporte. Se observa una capa pictórica lisa, aplicada a pincel, con un material oleoso, compuesto de pigmento más un aglutinante al aceite. El aspecto de la pincelada es fino y liso, no se aprecian texturas en la superficie de pintada de la obra. Uso de veladuras en los colores blancos del paño del niño Jesús y en las carnaduras."

80 No es imposible que en la península ibérica se pintara al óleo sobre lienzo en 1529, pero lo temprano de la fecha nos obliga a ser especialmente cautos al respecto y, por el momento, no dar la pintura de Sanlúcar como el original perdido de Holanda a pesar de los indicios expresados en este estudio. 


\section{BIBLIOGRAFÍA}

ÁVILA, A.; SÁNCHEZ-LASSA DE LOS SANTOS, A.; GARCÍA-FRÍAS CHECA, C.; RUIZ GÓMEZ, L.: El Divino Morales. Catálogo de la exposición celebrada en el Museo del Prado, Madrid, del 1 de octubre de 2015 al 10 de enero de 2016.

ÁVILA, A: "Una iconografía singular: la Virgen vestida de gitana", conferencia pronunciada en el Museo del Prado, 2016, https://www.youtube.com/watch?v=DDDKEOhwmLM (consultado el 01/12/2016).

DE ANDRADE MARTINS, R.: "O rinoceronte de Dürer e suas lições para a historiografia da ciência", Filosofia e História da Biologia, São Paulo, vol. 9, no 2, 2014, pp. 199-238.

CAIRATI, C. I Da Corbetta: una bottega di intagliatori nella Milano del Cinquecento. Università degli studi di Milano, 2014. Tesis doctoral.

CHECA CREMADES, F. (Dir.): Los inventarios de Carlos V y la familia imperial. Madrid, Fernando Villaverde Ediciones, 2010. 3 tomos.

DESWARTE, S.: "A mais homrrada cousa de similhante calydade que em parte alguma do mundo se posa ver", en Leitura nova de Dom Manuel I. Lisboa, 1997, pp. 87-89.

: Antonio de Holanda, Antonio Fernandes", en Ao modo da Flandes. Disponibilidade, inovaçao e mercado de arte (1415-1580): actas do congresso internacional celebrado em a reitoria da Universidade de Lisboa, (11-13 de abril de 2005), pp. 197-209.
FLOR, P.: "Un retrato desconocido de Isabel la Católica", Archivo Español de Arte, tomo 86 no 341, 2013, pp. 1-14.

GRAÇA MOURA, V.: "Retratos de Isabel. Imagens de uma Imperatriz", Oceanos, no 3, 1990.

: Retratos de Isabel e outras tentativas. Lisboa, Quetzal, 1994.

DE HOLANDA, F.: Do tirar pelo natural. 1549. Traducción de realizada por Manuel Denís en 1563: Del sacar por el natural. Ed. de John B. Bury, Madrid, Akal, 2008, p. 14, 90.

: Da sciencia do desenho. 1571. Edición de DE VASCONCELLOS, J.: Francisco de Hollanda. Da fabrica que fallece á cidade de Lisboa. Da sciencia do desenho. Oporto, Imprensa Portugueza, 1879, parte II, pp. 20-22.

: Carta del pintor Francisco de Holanda al rey Felipe II de España, 22 de enero de 1572 (en portugués). Archivo General de Simancas, Sección Estado, legajo 390, documento 87.

SEGURADO, J.: Francisco d'Ollanda. Lisboa, Edições Excelcior, 1970.

DESWARTE, S.: "Les De Aetatibus Mundi Imagines de Francisco de Holanda". Monuments et mémoires de la Fondation Eugène Piot, tome 66, 1983, pp. 67-190.

MARKL, D.: História da Arte portuguesa. Vol. 3. Lisboa. 1995. 
MARTín GONZÁLEZ, J. J.: "El palacio de Carlos V en Yuste", Archivo Español de Arte. Tomo 24, № 94. 1951, pp. 125-140.

MATEO GÓMEZ, I.: "Flandes, Portugal y Toledo en la obra de Luis de Morales. Las Vírgenes gitanas o del sombrero", Archivo Español de Arte, vol. 80, no 317, 2007, pp. 7-24.

OLIMPIO DOS SANTOS, R.: O Álbum das Antigualhas de Francisco de Holanda. Universidad de Juiz de Fora. Tesis doctoral. 2015.

PINCHART, A.: "Tableaux et sculptures de Marie" Tableaux et sculptures de Marie d'Autriche, Reine douairière de Hongrie (1558)", Revue Universelle des Arts, tomo 3, Bruselas, 1856, pp. 135.

REDONDO CANTERA, M.a J.: "La contribución de Isabel de Portugal al coleccionismo de pintura imperial", en Museo Imperial. EI coleccionismo artístico de los Austrias en el siglo XVI. CHECA CREMADES, Fernando (Dir.), Madrid, Fernando Villaverde Editores, 2013, pp. 121-145.

: "Artistas y otros oficios suntuarios al servicio de la Emperatriz Isabel de Portugal", actas, II Congreso Internacional de Historia da Arte. Portugal: Encruzilhada de Culturas, das Artes e das Sensibilidades. 1417 noviembre 2001, Oporto, Associação Portuguesa de Historiadores da Arte, 2001, pp. 657-662.

: "Linaje, afectos y majestad en la construcción de la imagen de la emperatriz Isabel de Portugal", en Congreso Internacional "Imagen y apariencia". Murcia, 2009.
: "Arte y suntuosidad en torno a la emperatriz Isabel de Portugal". Ars \& Renovatio, no 1, 2013, pp. 109-147.

SOLÍS RODRÍGUEZ, C.: "Iconografía mariana: la Virgen vestida de Gitana con el Niño y su versión en Luis Morales", Memoria Ecclesiae, no 21, 2002, Actas del XVI Congreso de la Asociación de Archiveros de la Iglesia en España, celebrado en Zaragoza del 11 al 15 de septiembre de 2000, pp. 373-384.

VANNUGLI, A.: "La subida al Calvario de Scipione Pulzone para Marcantonio Colonna", Archivo Español de Arte, vol. 85, no 340, 2012, pp. 303-328.

DE VASCONCELLOS, J.: Quatro dialogos. Da pintura Antigua. Oporto, Renascença Portugueza, 1896.

VeLÁzQUeZ-GAZTELU, J. P.: Historia Antigua de la ciudad de Sanlúcar de Barrameda escrita en el año 1760. Tomo 2. Sanlúcar de Barrameda, ASEHA, 1994.

: Fundaciones de todas las iglesias, conventos y ermitas de Sanlúcar de Barrameda escrita en 1758. Sanlúcar de Barrameda, ASEHA, 1995. 